\title{
Youth Psychology, the Impact of Identity Crisis in shaping future in Chetan Bhagat's Five Point Someone
}

\section{Mr.S.Venkateswara Rao ${ }^{a}$, Mrs. P.Vidyavathy ${ }^{\mathrm{b}}$, Mr. Imran Mahammad ${ }^{\mathrm{c}}$, Mrs. M.Rajitha Kantha ${ }^{\mathrm{d}}$, Prof. Dr.S. Jafar Ibrahim ${ }^{\mathrm{e}}$, Prof. Dr.N.S.Kalyan Chakravarthy ${ }^{\mathrm{f}}$}

\author{
a,b,c,d,e,f QIS College of Engineering and Technology (Autonomous) - Ongole,Prakasam Dt.,AP. India \\ e jafartheni@gmail.com, publicationsrj@gmail.com
}

Article History: Received: 10 November 2020; Revised 12 January 2021 Accepted: 27 January 2021; Published online: 5 April 2021

\begin{abstract}
The crisis of identity is one of the major issues of mankind.It does not confine to any single country, region, religion or ethnic group. Identity crisis prevails all over the world. It is also not confined to any particular age group people though the identity problem is predominantly visible in the life of younger generation. When we concentrate on the crisis of identity in Indian context, it has become the major problem of current educated youth.
\end{abstract}

So far, many writers of fiction have focused on the identity problem and Chetan Bhagat is no exception on this list. Since identity crisis, mostly, seems to be the major problem of the age group people between 18 to 30, Bhagat has appropriately dealt with it in his fiction. The educated younger generation, in general, face problems to get well settled in life after completion of their education.

\begin{abstract}
The students, now-a-days, have been facing numerous problems in their academic career itself to beat the crisis. Chetan Bhagat as a young entertainer, attempts to depict all their problems in his fiction. The problems include Mindless mugging (No room for creativity and Innovativeness), lack of Disciplinary Ethics, Rigidity, Monotony in Academic work, Students' Unrest, Fear, Insecurity, Controlled Stress and Suicide under Parental and Academic Pressure etc. For the purpose of my paper, I have chosen to study the identity problem crisis in youth of contemporary Indian Society and its portrayal in Chetan Bhagat's maiden novel, Five Point Someone-What not to do at IIT.
\end{abstract}

Keywords: Crisis of identity, Predominantly, Mindless Mugging, Rigidity, Contemporary.

\section{Introduction}

Indian English Literature is an attempt of presenting the real gems of Indian writing in English. From being an inquisitive native explosion, Indian English has become a novel form of Indian culture, and voice in which India speaks. While Indian authors-poets, novelists, essayists, dramatists-have been contributing significantly to world literature since the pre-Independence era, the couple of recent decades have seen a massive flourishing of Indian English writing. It should be pondered why, even today, people of India like to read Indian writing in English. The answer can be a simple one, that is, because of the familiarity with the geographical or cultural setting.

But is this the sole reason? People of India have an intense feeling of belongingness with Indian culture, Indian rituals, art, literature, with social structure, familial relations, with their functions and festivals, food and celebrations. Depiction of their culture in literary works persuades them to read the literary piece. Treatises of eminent authors and poets, whether in Hindi or English or in translation, are still read deep sentiments. What are those factors that make the works of Rabindranath Tagore, Sarojini Naidu,Toru Dutt, Mulk Raj Anand, R.K.Narayan, Anitha Desai etc. Many more rank among the world's best. The beauty and warmth of relations depicted in the works of these great writers truly showcases the mentality of Indian Society. Chetan Baghat is no exception on the list. The fictional writings of the recent Indo- English writers have registered a marked shift. Instead of presenting a typical Indian cultural background and traditional Indian cultural ethos, their work exhibits global apprehensions through the exhibition of multi-cultural reality. The modern writers of fiction exhibit a tendency of mixing fact and fiction that marks a shift fromthe traditional way of representation. Due to this, there came forth a new variety of fiction, called 'Popular Fiction'. Unlike 'Literary Fiction', which tends to be more academic, 'popular fiction' refers to the various fiction genres and types that have proved to be popular with a wide range of audience. Popular fiction is concerned with keeping the audience through the plot. 


\section{Literature Review}

Readers wish to see a distinct and interesting plot with plenty of complications and conflicts to keep them interested (Reeder, 2015). According to Jagdish Batra, the treatment of popular fiction is "simpler and it is nearer to normal life of people most of whom do not always speak grammatically correct and literary kind of language like the characters in most serious literature are represented doing" (Batra, 2012:109).

Since the purpose of the popular fiction is to appeal to the general public, it should be written in a way to present their true self and to keep the audience interested through the plot and Bhagat successfully applies all the norms of popular fiction. While the modern Indian writers in English like Salman Rushdie, Vikram Seth, Arundhati Roy, Anita Desai, Rohinton Mistry and Kiran Desai et al. are major literary figures, Chetan Bhagat, 'the biggest- marketing English language novelist in Indian history' emerged as a writer of popular fiction. When most of the stalwarts in fiction writing rely on India's past, using rich and elegant style with scholarly language, Chetan Bhagat has become popular by embracing the younger generation of India with ordinary English language that can be understood even by the teenage students.

\section{About the Author:}

Chetan Bhagat (born on 22 April 1974) is a well-known Indian author, editorialist and motivational speaker. All his novels- Five point Someone (2004), One Night @ The Call Center(2005), The 3 Mistakes of My Life (2008), 2 States: The Story of My Marriage (2009), Revolution 2020 (2011) and Half Girlfriend (2014) and his non-fiction What Young India Wants (2012),Making India Awesome (2015) have brought tremendous popularity to him.

The New York Times cited Bhagatas 'the biggest-selling English-language author in India's history'. The famous Times Magazine has added Bhagat in the list of 100 most persuasive people in the world (Bhagat,http://en.m.wikipedia.org/wiki/Chetan-Bhagat). Chetan Bhagat won 'Society Achievers Award' in 2005 for his Five Point Someone (2004). Fast Company, USA cited Bhagat as'100 most artistic people in Business' (Bhagat,http://en.m.wikipedia.org/wiki/Chetan-Bhagat).

Though Chetan Bhagat's fiction has been vehemently criticized by most of the stalwarts of Indian English fiction as containing unliterary, superficial and rude language, he is able to emerge as one of the popular novelists of India. All his novels are highly sold in the market and Jagdish Batra says, "Before the advent of Bhagat, in the genre of fiction, a book that sold 5,000 to 10,000 copies was considered an Indian bestseller, while all the novels of Bhagat were sold more than 2,50,000 copies each (Batra, 2012: 108).

Though his works seem hallow, and entertainment centered, they do portray the reality of the Indian culture and the underlying problems of the Indians, in particular, of the younger generation". Shashi Tharoor, a wellknown writer of fiction comments in an article, "To judge Bhagat by the yardstick of the quality, rather than the effectiveness of his prose is to miss what he is trying to do. He is saying something to young Indians that has not been said before in quite that way" (Tharoor, 2011).

The most notable quality of Bhagat's writing is that his works portray truth than fiction. The following are some of the major themes in Bhagat's fiction Love is one of the main themes of Bhagat that he has touched upon in all his novels. Since the concept of love has pervaded the life of younger generation, Bhagat, with hisfiction, seems to entertain them with love stories employing the colloquial language used by youngsters. From Five Point Someone to Half Girlfriend the love between the young male and female characters is clearly noticeable.

\section{Topic}

Almost in all the works of Bhagat, his characters seem to strive for liberty to their maximum extent. For instance, in Five Point Someone, the three friends, Ryan, Hari and Alok seem to liberalize themselves from the shackles of traditional IIT education system, in which students are compelled to be marks or grade-centered. In Two States: The Story of My Marriage, Chetan Bhagat deals with the complex love between Krish and Ananya, who belong to different states, differ invariably in cultural practices.

When both of their parents disapprove of their wish to get married, they feel insecure about their love and keep making attempts to get the approval of their parents. Throughout the novel Krish remains as a libertarian to meet success. Bhagat, in his fiction, clearly portrays the corrupt practices in the Indian society, particularly in politics.

In his Revolution 2020 and 3 Mistakes of My Life, Bhagat tries tohighlight the corrupt politics in Indian society. 


\section{Subtopic}

Five Point Someone: What not to do at IIT is Chetan Bhagat's magnum opus novel.

The novel is about three IIT students Ryan Oberoi, Hari Kumar and Alok Gupta, their years in IIT, Delhi, and their pressure of studies, family and relationships.

It explains, in particular, the struggle of the three friends to settle themselves with the IIT system of education to seek their identity. According to Chakravarthy, the novel "essentially deals with the globalized Youngistan and still there is a didactic purpose which is garbed under the satiric mode of narration."(Chakravarty, 2013: 122) and the novel has tried to "formulate the imperfectness of a seemingly excellent system" (Chakravarty, 2013: 122).

\section{Methods}

Hence, Chetan Bhagat has attempted to portray the struggle of the younger generation with the help of colloquial language, which is generally used by them to ridicule 'the system'. The characters Ryan Oberoi, Hari Kumar and Alok are considered the 'under- performers' with low GPA percentage. The novel deals with the dilemma of the three engineering students, who are in desperate quest of their identity in the IIT education system.

\section{Methodology}

The novel, in general, perfectly exemplifies the crisis of Indian graduates, who seek their identity in the system of education in which students are guessed to mug up the concepts all the time merely to vomit in the exams. It also depicts the defaults in the 'system' of education that has suppressed the students' creativity by forcing them to value grades more than anything else.

As the system of education has not changed from being merely marks or grade-centered, Bhagat has attempted to provide alternative methods to face it, even if is not totally possible to thwart it. He seems successful in applying his alternative strategies with the victims of the'system', i.e. his young characters. Despite their quest for identity, the three friends, Ryan,Hari and Alok do not seem to succumb to the traditional IIT system.

\section{Discussions}

However, it is absolutely true that they cannot get away from the reality (system). Being aware of this fact, they search for alternatives. In their first attempt, the three IITians prepare a systematic time- schedule for their daily routine to adjust themselves to the system. Ryan says: "Let us draw a line. We can study two to three hours a day but do other stuff, say sports... Or take part in events (like)debates, scrabble and stuff, an odd movie or something sometimes" (Five Point Someone (FPS), 40). When Alok seems disinterested in this strategy, Ryan further says; "We just draw aline (here). A day of classes, then three hours a day of studies and the rest is our time... Isn't It fair? A kind of decentralisation of education"(FPS, 40).

\section{Results}

When this strategy fails, it is their impulsive youthful behaviour that forces the three guys to part. Right from the ancient Indian education system, the students are expected to give respect to the teachers, obey their views and instructions. But it is however exact that a bad thing is to be rejected and a good thing is to be accepted whether it comes from an intellectual or from a layman.

Hence, the students need not obey the order of a teacher who misguides them. This is why Ryan, feeling that the instruction of his professors is not desirable, attempts to invent new ways to thwart 'the system' and convinces his friends to follow them. Hence, they attempt to apply another strategy, called 'Cooperate to Dominate' to thwart the 'system'. The plan seems to be a little ideal than the earlier one, though it does not eventually contribute to achieving their identity.

The three IITans assume that "the only way to take on the unfair system is through unfair means - which is Cooperate to Dominate or C 2 D"(FPS, 108).Thus their strategy includes sharing of assignments, courses and lab experiment observations. They decide to share the course responsibilities in a way that out of six, one has to attend two courses each: "One person will do each assignment by turn.

The others will simply copy it. Saves time, saves duplication of effort" (FPS, 10), Though it works out to some extent, the 'C 2 D strategy' does not bring them success in the grade-centered system of IIT education. Though these ideas to fight against the system seem impractical, the ideas do reveal the fact that the youth are not incapable of innovative thinking. For instance, Ryan's term paper on the impact of lubricant theory on scooter fuel consumption is a perfect example that showcases the creative thinking of engineering students. The point here is, though there are plenty of underperformers in Indian society with low GPA grade, it is also true that many of them 
are really brilliant in their innovative thinking. The recognition of student's innovative, experimental ideas should occur at reasonable levels.It is true that in the field of Engineering we find very few faculty, like Prof.Veera in Five Point Someone, who recognises the innovative ideas of Ryan.

“...Was it you who wrote the impact of lubricant efficiency on scooter

fuel consumption in your last term paper?" Prof. Veera said.

"Well, yes sir", Ryan replied.

"Is it true you actually tested the data on your scooter?"

"Yes I did sir. Not actually though."

"I like that, I really like that" (FPS,85)

This innovative Lubricant theory of Ryan clearly indicates that the students have the potential to prove their competencies, in spite of their underperformance in their course. Most of the professors of technical education do not allow any kind of change in the system of education. They desire to maintain the system as it is. Their perspective is to make the students mere 'muggers' and to respect the grade-centered system of education, and Bhagat tries to showcase this with the lecture of Prof. Dubey: "Respect the grading system. (If)You get bad grades and I assure you - you get no job, no school and no further. If you do well, the world is your oyster...otherwise there will be no oyster, just slush" (FPS, 11).

The words of Prof. Dubey are clear warning to the students to focus on only grades but not on any experimental, practical, innovative ideas. If the students' innovative ideas are well channelized, there is certainly a lot of scope for motivating the students towards their core studies thereby making them potential engineers with practical knowledge.

This is what, unfortunately, lacks in the system of engineering education in particular, in the entire education system in general. For instance, the conversation between Ryan and Prof. Vohra, a mechanical engineering faculty, vividly show cases the lack of teachers' encouragement to the students' innovative ideas

"What is this?" Prof. Vohra said.

Sir, this is modified screw-jack, Ryan said, "It can be connected to the car's battery..."

"Is this an electrical engineering class?"

"No sir but the end need is the same..."

"Is this an inside ignition engines class?"

"Sir, this is a new design."

"Really? And who told you to do that?"

(FPS, 118)

Being continuously questioned, without even partial approval of his innovative idea, Ryan gets frustrated, speaks a little harshly with the Professor: "There, it is useless now" (FPS, 118).

If there is no encouragement for their ideas from the faculty side, it is obvious that the students either dislike the faculty concerned or their subject itself or both, in the worst case. This is what happens in the case of Ryan in Five Point Someone. As Prof. Vohra did not recognize his experiment on screw-jack, Ryan is utterly disappointed, kicks the scooter stands as if it is Prof. Vohra's face.

He then does not also attend any of Prof. Vohra's classes further. Chetan Bhagat seems to be successful to showcase this crisis of educated youth in search for their identity. Now-a-days, the engineering graduates with their mere nominal degrees have been aimlessly roaming in the society in the quest of their identity.

Since they are unable to cope with the traditional, monotonous 'system' of education, and since there is no encouragement for their innovative ideas in the course of study, students some times, being frustrated, attempt to select wrong methods like mass copying and other things. Bhagat has exactly presented this issue with his three major young characters in the novel. 'Operation Pendulum' is a perfect example to depict this.

Ryan, Hari and Alok in desperation, decide to implement another strategy, despite their earlier strategies proving a total failure. Though they were hesitant to implement their strategy, "Operation Pendulum" which involves stealing of exam paper from Prof. Cherian office, they do it in desperation. The suicide of Samir, the son of Prof. 
Cherian and the attempted suicide of Alok clearly picturize the identity crisis of the present younger generation in the Indian society. Though both the guys' reasons for committing suicide are different, there underlies a basic fact that it is due to their inability to find their identity in the system of education. Alok seems to totally succumb to the grade-centered system of IIT education. When he fails to find progress in his course of study as a 'mugger'(Five Point Someone: p.71), he is attracted to get involved in' Operation Pendulum', along with Ryan and Hari.

When he thinks that all his hopes to win his identity are gone, he attempts to commit suicide. Samir's suicide, which is unknown to the society (except for Neha and Hari) is a pathetic one. The words in the letter that Samir wrote to Neha before his suicide are rather painful to read.

The innocent Samir, in the letter, depicts his delicate feelings: "I have tried three times to get into IIT. He (Prof. Cherian) cannot get over the fact that his son cannot handle Physics, Chemistry and Maths...I cannot do it Neha, no matter how hard I try, no matter how many years I study and how many books I read. I cannot get into IIT. And I cannot bear to see Dad's eyes". (FPS, 166)

He goes on to reveal his pain saying, "He (Prof.Cherian) saw thousands of IIT students in his life...but he doesn't see the hundreds of thousands who don't make it... What can I do? Keep on putting efforts until I die? Or simply die?"(FPS, 167). It is factual that many parents in Indian society like Prof. Cherian persuade their sons in particular, to study Engineering, Medicine or other courses for their career.

\section{Acknowledgement}

Most of the parents, while they do so, do not heed if their sons really wish to pursue the respective course suggested by their parents. Hence the poor guys, unable to cope with the course of their study, face numerous problems and in the worst case, they attempt to commit suicide. It is only when the consequences of their undesirable method (Operation Pendulum) hit the three dreamers hard that they come to realize that their approach to thwart the system is wrong though their ideas are good.

If the students' ideas, feelings, opinions are properly considered certainly they will not go for any wrong methods like mass copying, stealing the exam papers or other things, and they will not go to extravagances like committing suicide. Chetan Bhagat is totally successful in depicting all these sensitive issues, the predicament of students in the present generation struggling to seek the identity. Bhagat just asks the youth to listen to the voice of their heart.

\section{Conclusion}

Literature is a medium to bring revolution in the society. Literary endeavor must not betray the people from where it springs. Social commitment is certainly not incompatible with the aesthetic value of a literary work. Literature trying to depict reality should not be devoid of moral concerns that run as undercurrent of the people being portrayed. Just vulgarizing the reality is essentially crafty salesmanship.

People search their culture, their India, their rituals, their morals, in Indian writings in English and if Indian writings speak in the western overtone, then the literary works will not be able to quench the need of the heart of the common man of India but also shall infuse unrealistic gloominess in the seeker's mind. Chetan Bhagat aptly portrays India and her problems in his fiction works.

Bhagat, besides writing fiction, writes articles for the newspapers of English and Hindi focusing youth and national progress issues. He, now, has the honour of visiting various technical education institutions to give motivational speeches for the aspiring students. Before the advent of Bhagat, it is factual that there were very few young readers of fiction in India, while his linear, simple style of writing has become a platform for the younger generation to improve a taste for reading. It is certainly a remarkable achievement of Bhagat.

\section{Limitations and Future Studies}

Simultaneously, the path initiated by Bhagat, as Aroon Purie reports, "is now being followed by several others (writers)", for instance, "Amish Tripathi's Triology is breaking records and pulp authors such as Ravinder Singh and Anuja Chauhan are writing bestsellers..." (Purie, 2014: 3). Bhagat has become a helping hand for publishers too by "redefining India's publishing along the away" (Purie, 2014: 3).

It is true that Bhagat's publishers have created a market of their own though all his works are sold in the market at very low price i.e. below hundred rupees. The cursory perusal of Bhagat's novels creates the impression that they merely serve a sense of entertainment, for younger generation in particular. But if we look into his works, they will make us clear that he is trying to suggest us something for a fruitful change with his humorous representation of the life of Indians in general. Youth psychology and their mind set as IITians have been shown 
clearly in the novel and this can be expanded and projected in further studies in a different way as human generations and their mind sets are being changed in the upcoming years.

\section{References}

[1] Bhagat, Chetan. Five Point Someone. New Delhi: Rupa.2004.

[2] Batra, Jagdish. "Strategies of Popular Fiction in Chetan Bhagat's Three Mistakes of My Life". 21st Century Indian Novel in English: Emerging Issues and Challenges. Jagdish Batra (ed). New Delhi: Prestige. 2012. 108121

[3] Bhagat, Chetan. Wikipedia, the Free Encyclopedia.2014 http://en.wikipedia.on/wiki/Chetan_Bhagat

[4] Chakravarty,Suparna. “Globalization, Youngistan and Chetan Bhagat”. The Indian

English Novel Today. Prabhat K. Singh (ed) New Delhi: Authors press.2013.120-129.

[5] Purie, Aroon. "The Pulp Express", India Today. Volume No.36. 8 Sep 2014.3

[6] Reeder, E. "What is Popular Fiction?".Wise Geek: Clear Answer for Common Questions. A. Joseph (ed).Conjecture. 07 Jan 2015. http://m.wiseqeek.com/what-ispopular-fiction.html/.

[7] Tharoor, Shashi. "Behold a Phenomenon: Loving, Living, Scheming In Young India”. November 21, 2011. http://www.outIookindia.com/article/BehoId-A-Phenomenon-Loving-LivingScheming-In-Young-India/278918

[8] The Indian Journal of English Studies 49, VOL. XLIX, 2012.The Official Organ of the Association for English Studies of India, ISSN No.: L 0537- 1988.

[9] Jafar Ali Ibrahim S et al, International Journal of Psychosocial Rehabilitation, Vol 24, Issue, 8, "Recent Research Trends and Advancements in Computational Linguistics” April, 2020.

$$
* * * * *
$$

